\title{
A PERGUNTA ESQUECIDA: linguagem, alteridade e sujeito na educação especial ${ }^{1}$
}

\author{
Guilherme Mautone \\ Universidade Federal do Rio Grande do Sul - UFRGS \\ André Luís de Souza Lima \\ Universidade Federal do Rio Grande do Sul - UFRGS \\ Carla K. Vasques \\ Universidade Federal do Rio Grande do Sul - UFRGS
}

\section{Resumo}

O artigo procura sugerir uma outra possibilidade de pesquisa na área da educação especial ao chamar a atenção para a existência de perguntas anteriores no campo. Nesse sentido, a ideia de uma reorientação filosófica demanda certa recolocação da metafísica, ao suscitar a questão anterior sobre a natureza dos sujeitos da educação especial. O artigo pretende oferecer uma alternativa de resposta pelo viés de uma virada linguística, a partir das ideias de Wittgenstein. Essa virada apresenta-se, sobretudo, como crítica à perspectiva médica, seus desdobramentos metafísicos e, posteriormente, epistemológicos e éticos.

Palavras-chave: Educação especial. Sujeito. Linguagem. Filosofia da educação.

\begin{abstract}
This work aims to suggest another possibility of research in the field of special education by putting forward the existence of previous questions - philosophical questions - within the field. Thus, emerges the idea of a philosophical reorientation that demands a sort of metaphysical interest on the nature of the subject of special education. The work intends to offer an alternative response to that question through a linguistic turn on the field, substantiated by Wittgenstein. This linguistic turn is developed as a critical response mainly to the medical perspective on special education and its metaphysical and ethical employments.
\end{abstract}

Key words: Special education. Subject. Language. Philosophy of Education. 


\section{Introdução}

Pretendemos ao longo deste artigo apontar para uma nova possibilidade de pesquisa na educação especial, pensando particularmente em um tema tradicional da área que diz respeito ao sujeito desse campo. Nesse sentido, nossa proposta assume seu caráter preliminar e exploratório. O que será apresentado, desse modo, não configura os resultados de uma posição já consolidada; mas, sobretudo, um chamado à consideração e ao debate do que aqui se propõe.

Propomos a possibilidade de uma certa reorientação filosófica do campo a partir do recorte sobre a natureza dos seus sujeitos. Muito se tem produzido na área de educação especial sobre a ética (Voltolini, 2019), a historicidade (Mazzota, 1996; Januzzi, 2012) e os aspectos políticos (Kassar; Rebelo; Oliveira, 2019; Baptista, 2019) atinentes a ela. Porém, nosso trabalho dos últimos anos nos indica a possibilidade de uma reconsideração do itinerário dos estudos, das investigações e dos debates no campo. Essencial mencionar que esse trabalho esteve desde sempre vinculado à formação de professores, a nível inicial (graduação, licenciaturas) e continuado (extensão) ${ }^{2}$.

Este artigo está organizado em cinco seções principais. A primeira corresponde à introdução. Na segunda seção, apresentamos a questão da pergunta esquecida, ou seja, desenvolvemos a possibilidade de certa reorientação filosófica do estudo que enfoque os fundamentos do campo, recorrendo a um procedimento de redução metodológica, o que significa reconhecer a existência de uma pergunta primeira, anterior, sobre o sujeito da educação especial e a necessidade de que essa pergunta seja conduzida por uma investigação metafísica e lógica, antes de ética, histórica ou política. Na terceira seção faremos uma retomada de como se consolidou o campo da educação especial, mostrando suas modificações teoréticas em três perspectivas distintas com um foco no problema de seu sujeito; ela se encerra com uma discussão do entrincheiramento médico e dos seus efeitos na formação de professores (preeminência da medicalização, assujeitamento e mal-estar nas narrativas produzidas por professoras e professores). Na quarta seção fazemos uma apresentação bastante sumária de um caso escolar, que envolve a construção de uma narrativa pela aluna e pelo professor e enseja uma investigação sobre o estatuto da linguagem. $\mathrm{Na}$ quinta seção, ousaremos conduzir essa investigação, propondo uma resposta provisória a essa pergunta, principalmente a partir de uma conversa possível entre a filosofia contemporânea da linguagem, consolidada nos empreendimentos de maturidade de Wittgenstein e seus debatedores.

\section{A pergunta esquecida}

Nos inspiramos no importante trabalho de M. Gueroult, Descartes selon l'ordre des raisons, de 1992, que apresenta a ideia de que a filosofia de Descartes se encontra metodologicamente ordenada segundo uma certa ordem das razões, para considerar a existência de uma pergunta anterior, muitas vezes esquecida, no campo da educação especial. 
Embora o empreendimento de Gueroult pretenda mostrar que a filosofia de Descartes se encontra inserida numa problematização filosófica de cariz epistemológico - já que se volta à delimitação das próprias condições de fundamentação do conhecimento, apresentando assim a existência de uma estrutura que subscreve o modo de proceder cartesiano -, tomamos aqui a evidenciação dessa estrutura como um expediente para sugerir uma reorientação filosófica dos estudos sobre educação especial. Essa sugestão, inspirada em Gueroult, é a de que existe uma pergunta anterior que concerne ao campo e, no mais das vezes, é ou adiada ou respondida muito preliminarmente. Neste último caso, sua resposta apresenta uma série de pressupostos que, considerando a ordem de investigação, não foram ainda respondidos e, nesse sentido, apresentam-se como postulados implícitos, elípticos. E, por serem postos assim, trazem obscuridade às investigações empreendidas pelo campo.

Ao se voltar à filosofia de Descartes, Gueroult menciona a pretensão filosófica do pensador em fundamentar um sistema de conhecimento capaz de apresentar coesão interna, ao modo matemático, no qual as proposições se encontram encadeadas umas às outras de acordo com uma ordem das razões. Ele diz:

A filosofia não poderá ser cientificamente construída enquanto um bloco unificado de certezas em conformidade com a indivisibilidade da verdade ao menos que seja estabelecida, como na matemática, por uma rigorosa cadeia de proposições de acordo com a ordem das razões. Ela deve, portanto, romper com a costumeira construção de trabalhos tradicionais, notadamente aqueles inspirados por uma doxografia, e que se encontram divididos em capítulos nos quais cada um exaure um tópico de investigação, colocando-os justapostos simplesmente segundo uma ordem ritual onde, na verdade, nada se encontra conectado (Gueroult, 1984, p. 5 e 6, itálico nosso).

A introdução da noção de uma cadeia rigorosa de proposições a partir da qual se possa consolidar o conhecimento suscita, assim, o problema epistemológico do fundacionalismo; exigindo que se explique onde essa cadeia se inicia, qual seu ponto de partida ou, então, qual seria sua fundação. Ora, se esse ponto de partida suscita uma proposição ainda não incluída na própria cadeia, então a cadeia como um todo é remetida ao infinito, uma vez que exigiria sempre uma outra proposição anterior como fundação (regresso ao infinito). De modo análogo, se esse ponto de partida suscita uma proposição já dada na própria cadeia, então a cadeia se fecha sobre si mesma, tornando-se circular (circularidade). Assim, buscar uma proposição que não exija demonstração prévia ou uma proposição que não esteja presente numa outra que se quer demonstrar corresponderia a um critério minimamente necessário para o funcionamento desse tipo de sistema ${ }^{3}$. Com efeito, é possível afirmar com certa legitimidade que a discussão fundacionalista que Gueroult aponta em Descartes toma uma viragem metodológica. Sobretudo quando consideramos a existência de um método analítico - típico da geometria e correspondente ao que ele chama de ordem das razões - e um método sintético, doxográfico (Gueroult, 1984).

Ainda que esteja bastante claro que as considerações de Gueroult sobre a ordem das razões pretendem discutir a filosofia de Descartes e sua adesão ao método analítico da 
geometria como um modo rigoroso de proceder em filosofia e em ciência, pensamos ser apropriado tomar a noção de ordem das razões como um expediente que busca por clareza, coerência e organização para determinados campos de investigação. Num sentido derivado, demandar de um campo e dos discursos que são nele produzidos que se apresentem sob a ordem das razões significa, no limite, demandar que ele se abra a uma consideração sobre sua própria produção discursiva e, sobretudo, que ele atente para os critérios teoréticos que organizam essa produção - inclusive em uma dimensão estrutural. Se existem, por exemplo, ao longo de uma proposta teorética, uma série de pressupostos não demonstrados, premissas implícitas ou conceitos que sob análise apresentam ambiguidades ou incoerências teóricas, então o esclarecimento desses aspectos poderá auxiliar na busca de maior precisão e coesão argumentativa dessas propostas e discursos. Com efeito, quando tomamos a filosofia enquanto uma atividade intelectual de segunda ordem e capaz de trazer à frente questões que não estão sendo colocadas inicialmente pelos outros campos e práticas (Carroll, 2010), também se torna legítimo sugerir que a filosofia em muito poderá auxiliar as demais áreas e campos ao apontar a existência de perguntas que não estão mais sendo colocadas pois tomadas como já respondidas. O empreendimento filosófico, ao recolocar a pertinência de algumas questões, inaugura também a oportunidade de certa avaliação do próprio campo e de uma recalibragem conceitual das teorizações que ele avança.

A recolocação da pertinência de uma pergunta, por exemplo, sobre quais seriam os sujeitos da educação especial, permite-nos retroceder metodologicamente no sentido de uma ordem das razões e, assim, sugerir que o desafio de estabelecer uma ética para esse campo depende, antes, da assunção de uma certa resposta para essa questão. Falar, portanto, de uma ética da educação especial que prescinda de uma caracterização mais rigorosa a respeito da natureza de seu sujeito, parece-nos corresponder a uma investigação que, embora necessária, mostra-se como secundária na ordem das razões. Com efeito, pretendemos, no que se segue, retomar a pergunta pelo sujeito da educação especial, oferecendo para essa questão alguns caminhos possíveis para uma resposta preliminar.

\section{Genealogia do campo: perspectivas que fundamentam o especial}

Os estudos que procuram localizar historicamente uma origem para a educação especial geralmente o fazem considerando o advento da modernidade - mais propriamente ligando-a à eflorescência do iluminismo -, o que coincide com o momento em que o conceito de deficiência passou a ser descrito no campo das ciências naturais. Tal movimento, por sua vez, implicou o surgimento de uma modalidade clínico-educacional de atendimento e uma área de saber correspondente, o que se deu na conjunção entre pedagogia, medicina e psicologia. A partir dessa racionalidade híbrida, foram criadas diferentes categorias e procedimentos com o fim de fundamentar práticas institucionais em asilos, manicômios e escolas especiais, bem como a identificação do público-alvo e a formação dos especialistas. (ULLRICH; VASQUES, 2017). 
Plaisance (2015), argumenta que os serviços de educação especial, por sua vez, foram estabelecidos a partir dos princípios da separação e do capacitismo. Nesse caso, a deficiência é considerada anormalidade e aqueles considerados anormais, diferentes ou mesmo ineducáveis frequentariam classes ou escolas exclusivamente especiais. Tais instituições tinham por objetivo aproximar crianças e adolescentes com deficiência a um padrão considerado normal de desenvolvimento, de comportamento e de inserção na cultura.

[...] as instituições para pessoas deficientes, independentemente do tipo de deficiência, seguiram por muito tempo esse modelo de segregação e de isolamento. Em outras palavras, a representação das pessoas como "anormais" acarretou a necessidade de colocá-las em instituições também incomuns. Aprofunda-se essa análise, tomando o exemplo da Educação: nessa área, a atribuição de "especial" indica uma característica negativa das crianças implicadas e, ao mesmo tempo, define um lugar de educação (estabelecimento ou turma), ele próprio definido sob a égide do "especial", como em um jogo de espelhos (Plaisance, 2015, p. 232).

Conforme sugere o autor, a palavra especial contrai o peso das designações historicamente atribuídas àquelas pessoas percebidas como inerentemente obstaculizadas no que concerne à educação, ao trabalho e à vida cotidiana; obrigando a uma clivagem entre grupos e rotulando-as como aquelas para as quais são dirigidos espaços e serviços específicos e, portanto, reconhecimento diferenciado. Pelo mesmo percurso, o desgaste de expressões como anormal, retardado, débil, incapaz, ineducável, entre outras - levando em consideração o quanto já foram valorativamente neutras e hoje são pejorativas -, permite entender o contexto estigmatizante em que foram forjadas (Plaisance, 2015). Enquanto representações em negativo ${ }^{4}$ das pessoas que são assim identificadas e separadas, essas designações se fundamentam naquilo que Goffman (2008) definiu como estigma: atributo constituído por uma marca real ou metafórica que lança descrédito sobre uma pessoa ${ }^{5}$. Esse atributo, na definição do autor, sobrepõe-se a todos os demais, identificando e reduzindo quem o apresenta a uma categoria social classificada como indesejável no tecido de relações grupais mais amplas. Efetua-se, assim, a separação entre normais e anormais:

[...] um indivíduo que poderia ter sido facilmente recebido na relação social quotidiana possui um traço que pode-se impor a atenção e afastar aqueles que ele encontra, destruindo a possibilidade de atenção para outros atributos seus. [...] Nós e os que não se afastam negativamente das expectativas particulares em questão serão por mim chamados de normais (Goffman, 2008, p. 14, itálico nosso).

Uma vez que nos entendamos como parte do grupo dos normais, Goffman explica, nossa atitude em relação àqueles que apresentam um estigma é a de quem os percebe como não completamente humanos, reproduzindo ações que diminuem suas chances de vida (Goffman, 2008). Resta, assim, a suavização dessas barreiras pela ação social benevolente e a criação 
de teorias e ideologias que deem conta de explicar o que é tomado como inferioridade; racionalizando, inclusive, animosidades advindas de outras diferenças, como a de classe social (Goffman, 2008).

Tomando o mote trazido pela ideia de anormalidade, Bueno (2003) nos fala sobre a produção de uma identidade anormal (se é que há alguma) enquanto construção histórica continuamente dependente da existência de algum critério pelo qual o meio social diferenciou aqueles que apresentavam uma ou mais características não encontradas na maior parte dos membros do mesmo meio. Em verdade, essa produção se daria não apenas pela existência dessa característica, mas por suas consequências no que diz respeito às possibilidades de participação na construção coletiva das condições de sobrevivência e reprodução do grupo. Em consonância com Goffman, Bueno (2003) também sugere que tais peculiaridades são entraves a um processo de humanização, uma vez que são percebidas como não universais e um estado menos frequente na vida dos seres humanos. Estaríamos, por essa definição, ante quadros patológicos, para os quais o modelo de compreensão vigente em cada época é aquele então chamado de doença. Varia, desse modo, conforme a perspectiva de maior prevalência em cada época, a explicação para a existência da doença, bem como o tratamento oferecido e os responsáveis por aplicá-lo. Há épocas e sociedades em que ela é entendida como possessão demoníaca; em outras como desequilíbrio em relação à totalidade do ser humano; também se encontra a ideia de uma reação do organismo sob perturbação; mais modernamente, temos a noção de um desvio quantitativo do funcionamento regular em termos orgânicos, sociais ou psíquicos (Ferreira, 2016, p. 75-107). Independentemente disso, nos explica Bueno (2003), a procura pela explicação da doença sempre acarretou uma tecnologia de intervenção sobre ela. Todavia, no que diz respeito à ciência moderna, se, por um lado, retirou-se do campo do sobrenatural a prevalência discursiva - contribuindo efetivamente para o aumento das possibilidades de sobrevivência a partir da descoberta de agentes nocivos -, por outro, uma “[...] concepção hegemônica moderna de anormalidade social tem utilizado como base o paradigma biológico, na medida em que essa ciência já teria chegado a alto nível de certeza na distinção entre o estado normal e o estado patológico" (Bueno, 2003, p. 164). O problema dessa perspectiva é que nem mesmo pelo viés biológico se pode ratificar a pretensa objetividade de uma concepção de anormalidade (doença), posto que não há como separar manifestações orgânicas das condições oferecidas pelo meio. Isto é, respostas orgânicas adequadas ao meio podem passar a ser inadequadas caso as condições do meio sejam modificadas, de modo que não há ser vivo ou meio que sejam normais ou anormais fora dessa relação (Bueno, 2003, p. 165 e 166). Por sua vez,

[...] o conceito de anormalidade social não vai, historicamente, apenas se refinando ou se tornando cada vez mais preciso, mas vai se modificando, na medida em que as condições sociais vão sendo transformadas pela própria ação do homem e que geram novas necessidades na relação indivíduo / meio social (Bueno, 2003, p. 166). 
Habitando a mesma esfera da noção de anormalidade, a conceituação de deficiência recebe diretamente os reflexos dessas perspectivas enquanto formas distintas de reconhecer pessoas em tal condição. Como campo de estudo e arena da luta por direitos sociais, constituise no entrecruzamento dos discursos que a representam e se materializa no oferecimento de serviços cuja natureza pode ser inferida pelo modo como se responde a três perguntas: A quem esses serviços são destinados? Quais são eles? Onde eles serão oferecidos? Não tomamos aqui tais perguntas apenas com fins retóricos, porque para nós elas precipitam questões anteriores e mais fundamentais sobre o sujeito do campo e sobre os contextos nos quais foram elaboradas discursividades teóricas específicas. Coloca-se, diante disso, uma necessidade metodológica em investigá-las, uma vez que por meio dessa investigação poderão ser minimamente esboçadas as tramas que consolidam o tecido social. Em Wittgenstein (2009), à noção de alteridade cabe uma atribuição basilar. Para ele, o processo de significação (linguística) se fundamenta contextualmente ao suscitar uma forma de vida humana, representada por um grupo de comunicantes. Endossamos, portanto, aquelas posições filosóficas que entendem a alteridade como indispensável na pesquisa e na descrição daquilo que compõe a explicação de algo.

Voltando às três perguntas mencionadas, algumas de suas respostas parecem mostrar ao menos três perspectivas que têm coexistido na disputa por sentido, pertinência e espaço nos discursos sobre a educação especial. Desse modo, destacamos: a perspectiva caritativa, na qual a pessoa com deficiência geralmente é entendida como acometida por um infortúnio ou fatalidade, necessitando de apoio da filantropia ou da caridade pública; a médica, na qual a possibilidade de tratamento e normalização da condição de deficiência rege os recursos e a atenção profissional; e, finalmente, política, pela qual se percebe a pessoa com deficiência como detentora de direitos e necessidades a serem asseguradas pelo Estado ou pela sociedade (Ullrich; Vasques, 2017).

No que diz respeito ao assunto aqui tratado, é preciso apontar certa inadequação filosófica nas perspectivas que estofam o campo da educação especial com discursos fundados em reduções biológicas, médicas e neuronais, uma vez que reduzem o conceito de sujeito a um materialismo biológico empobrecedor. Nessa redução, as singularidades são transformadas em meros sintomas, indícios da patologia e da anormalidade, que devem ser tratados pela via medicalizante e farmacológica. A recolocação da pergunta pelo sujeito, além de colocar em suspeição a adequação dessa imposição teorética, sugere também a existência de outros modos de responder a essa pergunta. Compreendê-lo, portanto, pela via da inserção na linguagem como um sujeito de enunciação - um sujeito que fala, que se insere em jogos de linguagem e participa de uma forma de vida humana eminentemente linguística, habitando e reinventando os contextos enunciativos - implica num afastamento radical dos reducionismos dos discursos médico, caritativo e mesmo político, os quais por vezes se equivocam ao não se interrogar sobre a existência de uma identidade do deficiente. Ademais, muitas vezes esses discursos afastam essa interrogação sob a égide de um reconhecimento lesivo, incapaz de oferecer as mesmas condições de existência que são oferecidas ao grupo dos considerados como normais. 
O discurso médico, sobretudo, coloca-se no campo da educação especial enquanto portador de objetividade científica e neutralidade teórica, ocultando a contextualidade (aquelas condições socioculturais, históricas e situacionais) do que se dá a perceber dentro da escola, nos enunciados dos alunos e nas relações entre eles e os professores. Essa aparente neutralidade de atitudes teoréticas e objetivistas do discurso médico configura, na verdade, até mesmo uma realidade escolar marcada pelo diagnóstico médico-psicológico que tem recebido atenção central na definição das práticas pedagógicas, limitando as formas de conhecer em educação especial. Esvaziados de seu caráter enunciativo, o comportamento, o gesto e os pormenores de uma vida cotidiana são, nessa perspectiva, enquadrados, depurados pelos inúmeros questionários e escalas de medida, a ponto de perderem o valor de palavra dirigida a alguém. O que era diálogo transforma-se em reação, perdendo-se, assim, a especificidade contextual e humana da aprendizagem. Apesar disso, tal temática é silenciada nas pesquisas, bem como nos espaços de formação inicial e continuada, e os manuais classificatórios, com bases naturalistas, circulam sem maiores questionamentos quando se trata de crianças e adolescentes destoantes do aluno tomado como ideal (Vasques; Lima, 2018).

À título de exemplo de tal tendência, poder-se-ia indicar como ela se incorpora linguisticamente. Na língua portuguesa, por exemplo, evidencia-se um modo de emprego da linguagem que substantiva tanto a doença crônica, como o transtorno mental. O mesmo não ocorre com as doenças episódicas, as quais muito raramente ou nunca são empregadas enquanto substantivos. Assim, um uso substantivante da doença crônica e dos transtornos mentais - o/a diabético/a, o/a hipertenso/a, o/a bipolar, o/a autista, o/a psicótico/a configura-se enquanto um indício linguístico do processo social de estigmatização, retomando Goffmann (2008). Mas são indícios, sobretudo, de um reducionismo da complexidade mental, psíquica e, principalmente, existencial ao materialismo biológico que fundamenta as ciências médicas, uma vez que parece reduzir a existência de um indivíduo à sua doença ou transtorno. De um ponto de vista ontológico, isso corresponde a tomar a totalidade do ser (substância) por um de seus atributos.

Há um modelo de saúde e de doença nas ciências médicas. Ele classifica doenças como aquilo que tem marca orgânica e pode ser identificado via aferições técnicas específicas. Doenças podem ser subclassificadas em crônicas ou episódicas. Diferentemente, é uma condição analítica da definição de transtorno mental a inexistência de marca orgânica, e sua identificação se dá via conjuntura de sintomas. No entanto os transtornos mentais, embora sejam assim analiticamente definidos, ingressam na gramática também com formas substantivadas, assim como as doenças crônicas. Não é possível, portanto, a partir desse desdobramento da definição de transtorno mental, classificá-lo como algo atinente ao par normalidade-anormalidade, ou algo que suscita a relação saúde e doença, no mesmo sentido em que as doenças. Isso não significa, contudo, que um quadro sintomático de transtorno mental não deva ser alvo de atenção médica, psicológica ou de saúde pública. (DSM-5, 2014, p. 20-22; CID-10, 2018). 


\section{Não lê, mas escreve}

Era um contexto de sala de aula, a nível profissionalizante. Sendo uma aula de preparação para o trabalho, os alunos passavam um período do curso (dois ou três meses) numa empresa na qual faziam um estágio de experiência e um outro período (também de dois ou três meses) na escola. A cena que relatamos diz respeito à primeira semana do retorno à escola depois do período de trabalho. O professor recebe os alunos e propõe que produzam um relato sobre o período em que eles trabalharam. Como havia alunos em diferentes níveis de alfabetização, o relato poderia ser realizado de formas distintas (desenhos, escrita, colagens, pinturas, etc.). Nesse momento, uma das alunas que sempre carregava um caderno e canetas, interpela o professor e diz: "Professor, eu não leio. Mas eu escrevo". Ao passo que o professor responde: "Mas eu leio. Então tu escreve pra mim, que eu leio o que escreveu, ok?”. A aluna então realiza a atividade e entrega, alguns minutos depois, o seguinte relato:

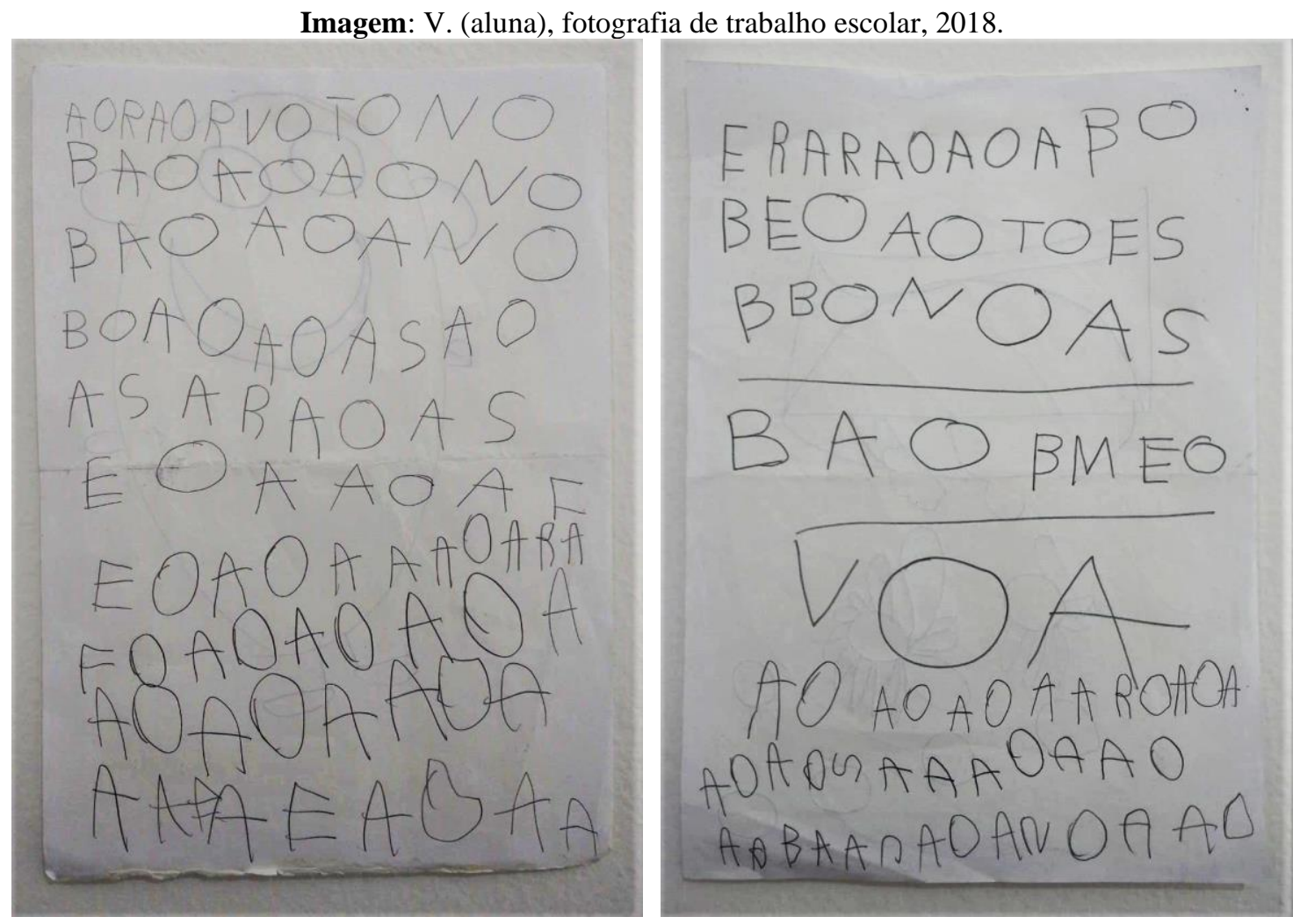

Fonte: os autores.

Quando a aluna entrega seu relato aparentemente satisfeita com a realização da atividade, pergunta ao professor: "Tá bom assim?". E o professor responde: "Ah sim! Que legal o teu relato, então tudo foi ótimo lá na empresa?". A aluna respondeu, franzindo o cenho e meio desconfiada, como se quisesse indicar que o professor não havia lido completamente o relato: 
"Não... teve coisa que não foi tão legal assim." A aluna retorna ao trabalho de escrita, inscreve um segundo tempo, grafado entre traços e, por fim, a partir da palavra VOA, registra "o que não foi tão legal assim".

Nesta experiência dialógica, tomamos o relato feito pela aluna como uma escrita, ou seja, algo que exige um autor e um leitor. Como algo que se dirige a alguém, que vem a partir de uma demanda simbólica instaurada pelo professor e exige dos alunos um esforço de elaboração de suas próprias experiências. Estabelece-se aí uma relação pautada sobretudo pela linguagem. Essa postura, que atribui ao relato da aluna uma condição de escrita, de palavra endereçada a alguém, reconduz a aluna a um lugar no qual ela não é reduzida existencialmente à sua condição ou a um conjunto de sintomas. Esse lugar de elaboração pressupõe que a aluna se encontra num lugar a partir do qual pode construir sentido. Essa experiência, se tomada desde uma perspectiva medicalizante, poderia ser apontada como o momento em que fica evidente um sintoma do seu transtorno ou lesão, ou seja, uma manifestação de sua anormalidade. Critica-se aqui esse tipo de redução da produção da aluna em questão, pois tomá-la enquanto evidência da sua anormalidade corresponderia a um grosseiro reducionismo das dimensões contextuais e significativas da palavra e dos enunciados na construção de laço. Queremos indicar, portanto, que os enunciados da aluna durante seu relato evidenciam: o fato de ela ter feito o seu relato à sua maneira, do modo como ela pode produzi-lo, o que nos dá uma razão suficiente para tomar a sua linguagem enunciada, performada, como legítima; e não nos dá nenhuma razão para alijá-la de um lugar de elaboração, de autonomia, de inserção na linguagem.

\section{Sujeitos que enunciam}

A partir disso, pensar sobre a linguagem parece-nos, portanto, fundamental para escapar de um modo de entender as relações educativas como calcadas no tecnicismo cientificista e biologizante. No contexto da escola, esse reducionismo opera efeitos segregadores e estigmatizantes, desterrando os alunos de lugares de elaboração simbólica autônomos próprios das relações escolares, de ensino e aprendizagem, e, principalmente, da humanidade. O estigma, como já vimos em Goffman, perfaz assim suas insidiosas e discretas desumanizações. Devolver ao aluno a sua oportunidade de elaborar é convocá-lo novamente para a linguagem. Pensar sobre o sujeito a partir daí é, portanto, oferecer uma possibilidade de resposta à pergunta esquecida pelo campo da educação especial. Nesse sentido, certos empreendimentos da filosofia contemporânea nos oferecem elementos para uma tentativa de resposta que preconiza a linguagem como algo inescusável na educação.

Conforme nos lembra Cavell, um dos mais relevantes comentadores da filosofia tardia de Wittgenstein, "Investigações [Filosóficas] é uma obra que tem início com uma cena de herança, a criança herdando a linguagem" (Cavell, 1997, p. 62). Pois o que inaugura o texto de Wittgenstein é uma citação das Confissões de Santo Agostinho, na qual o pensador medieval do período patrístico rememora suas primeiras experiências de aprendizado da linguagem marcadas por um tipo de jogo complexo de entonação de sons, vozes, gestos e 
mímicas que, ao cabo, mostraram-no que os objetos eram indicados, designados, por palavras enunciadas.

Assim, com a recuperação de uma cena de aprendizado da linguagem contada por Santo Agostinho, Wittgenstein pretende indicar ao seu leitor o que há de peculiar e de premente nessa cena. Embora ela diga respeito ao aprendizado da linguagem por uma criança, ela também dá ensejo para que se considere filosoficamente esse aprendizado, no sentido de que ele subscreveria igualmente um tipo particular de imagem sobre a própria natureza da linguagem. Se Santo Agostinho aprendeu que a linguagem funcionava através de um jogo complexo de designações, no qual as palavras substituíam os objetos, então o que subjaz tacitamente a esse aprendizado é a ideia de que a linguagem é essencialmente um rígido mecanismo referencial capaz de indicar os objetos, ou designá-los, através de um processo de substituição simbólica. Essa seria, portanto, a parcela filosófica da cena agostiniana retomada por Wittgenstein e que revelaria o modo como se estabelece o processo de significação linguística. No entanto, o trecho das Confissões não confere visibilidade somente a uma cena de herança particular - uma criança aprendendo a falar, aprendendo a usar a linguagem -, mas também sugere ao leitor o fato de que nós todos usualmente compreendemos a linguagem desse modo, enquanto um rígido sistema simbólico onde cada palavra designa necessariamente um objeto e, mutatis mutandis, para cada objeto deve existir uma palavra. Por essa razão, o principal tema a chamar a atenção do leitor em sua leitura inicial de Investigações Filosóficas deverá consistir naquele esforço de Wittgenstein em ganhar esclarecimento sobre esse processo subjacente à discussão da natureza da linguagem, a saber, o processo de significação linguística. Para Wittgenstein, a passagem de Santo Agostinho, consegue apresentar uma espécie de modelo consensualmente aceito de como entendemos a linguagem e de como tendemos a pensar sobre ela porque a passagem apresenta de modo taxativo uma "particular imagem da essência da linguagem humana" (Wittgenstein, 2009 , p. 5e $)^{6}$. Assim, aquilo que na linguagem garantiria o significado de uma palavra, a sua significação, é supostamente o fato de que toda palavra nomeia um objeto específico, estando com ele numa relação substitutiva. Wittgenstein, nesse sentido, foi preciso: "É o objeto que a palavra substitui" (Ibidem) na cena narrada por Santo Agostinho. Com isso, garante-se o rigor da significação linguística do meio simbólico.

É evidente que a incidência do texto agostiniano como uma espécie de inauguração para Investigações Filosóficas não é vã, muito menos um truísmo; mas Agostinho foi introduzido deliberadamente por Wittgenstein. Seu esforço, em especial ao longo da primeira parte do livro, consistiu em sensibilizar o leitor para o fato de que nossa herança filosófica dessa certa imagem sobre a natureza da linguagem presente nas Confissões é equivocada. Ademais, se levarmos em consideração o prefácio de Investigações Filosóficas - onde encontramos a necessidade de uma reparação pelos "graves erros que [eu] publicara" (Ibidem, p. 4e) no seu primeiro livro, o Tractatus Logico-Philosophicus -, também seremos obrigados a reconhecer o esforço da filosofia wittgensteiniana tardia em mostrar o quão filosoficamente inadequada é a ideia de que a linguagem depende de uma "teoria da representação que requer um isomorfismo formal e estrito entre o sistema das proposições elementares e a totalidade dos fatos possíveis" (McGinn, 1997, p. 49); ou ainda, de que na linguagem "um nome está por 
uma coisa, e outro nome por outra coisa" (Wittgenstein, 2001, p. 26). A filosofia tardia de Wittgenstein é, portanto, uma filosofia de retomada, de revisão e de reparação. Contudo, qual será a especificidade dessa reparação filosófica e, também, como ela será empreendida pelo pensador austríaco?

Para McGinn e também para Stern, outros dois relevantes comentadores de Wittgenstein, as ideias tractarianas, bem como aquela concepção filosófica inicial sobre a linguagem, serão reparadas na filosofia tardia através da enumeração atenciosa e da experimentação sucessiva de exemplos, casos concretos, situações imaginadas, tão típicos de Investigações Filosóficas, e que procuram urdir na própria tessitura desse texto uma reflexão sobre a linguagem desde sempre amarrada à concretude de seus usos em cenas e contextos particulares (McGinn, 1997; Stern, 2004). Essa escolha metodológica de Wittgenstein condiz, parece-nos, à própria aplicação de sua nova maneira de pensar a linguagem e a uma tentativa urgente de se afastar daquela concepção formalista que marcara seu pensamento no Tractatus LogicoPhilosophicus.

Nesse sentido, a incidência das noções inéditas de jogos de linguagem e formas de vida na filosofia tardia de Wittgenstein procuram, cada qual a seu modo, deflacionar a perspectiva tractariana ao darem proeminência para o fato de que a linguagem ocorre (e deve sempre ser considerada) sob o pano de fundo das atividades concretas e das práticas que arregimentam seu uso. A interpretação de McGinn sobre os jogos de linguagem será, em nosso ver, preciosa para que se compreenda com mais cuidado a dimensão dos comprometimentos de Wittgenstein em Investigações Filosóficas e o teor radicalizante de sua reparação. Pois, para McGinn, o

conceito wittgensteiniano de jogos de linguagem serve muito claramente como uma maneira de sobrepor e de contrariar a ideia da linguagem enquanto um sistema de símbolos significativos que pode ser considerada em total abstração do seu emprego efetivo. Em vez de abordar a linguagem como um sistema de signos dotados de significado, somos incitados a pensá-la in situ, incorporada nas vidas dos que a falam (McGinn, 1997, p. 45).

O ponto aqui consiste em apresentar a ideia de que o processo de significação linguística é mais adequadamente explicado quando mostramos (indicamos, apontamos) a incorporação da linguagem nas práticas dos falantes, pensando-a como estando localizada contextualmente. Ademais, a defesa da ideia de que o processo de significação se encontra garantido formalmente, sem uma consideração sobre o uso da linguagem em contextos específicos, suscita o problema ainda maior de explicar como, no limite, a linguagem apresentaria ela mesma significação num sentido humano. Afinal, a linguagem é essencialmente uma criação humana que se naturaliza, torna-se uma segunda natureza; mas não é, intrinsecamente, algo que antecede a história da forma de vida humana. É assim que McGinn entende, acompanhando Wittgenstein, que pensar a linguagem em termos rigorosamente abstratos implicaria na própria morte da linguagem. 
A tendência em isolar a linguagem, ou em abstraí-la dos contextos nos quais ela vive ordinariamente, encontra-se vinculada a adoção de uma atitude teorética em relação a ela e, também, a nossa urgência em explicar como esses meros signos (essas meras marcas) podem adquirir um poder extraordinário de significar ou de representar alguma coisa. O objetivo de Wittgenstein é nos mostrar que através desse ato de abstração, nós damos as nossas costas para tudo aquilo que é essencial ao funcionamento da linguagem; é o nosso ato de abstraí-la do seu emprego dentro das nossas vidas ordinárias que acaba por transformá-la em algo morto, cuja habilidade de representar agora clama por explicação (Ibidem).

Desse modo, os jogos de linguagem que Wittgenstein entretece ao longo de Investigações Filosóficas são, basicamente, pequenas narrativas, exemplos de diminutas cenas, feito uma coleção de tableaux vivants que apresentam contextos de uso da linguagem, situações concretas de sua aplicação. Por exemplo, o primeiro jogo de linguagem discutido por Wittgenstein é o do vendedor de maçãs; que é apresentado logo após a citação de Santo Agostinho como um expediente argumentativo a fim de mostrar qual seria a implicação, na prática, num contexto vivido, da aceitação da tese de que a linguagem opera sempre e necessariamente pela função designativa. Assim, nesse primeiro caso, o jogo de linguagem do vendedor de maçãs evidencia o quão inadequada e antinatural é aquela concepção, uma vez que a cena é diametralmente distinta do que se passa na vida real quando compramos alguma coisa, empregando a linguagem cotidianamente.

Agora pense no seguinte uso da linguagem: Eu peço que alguém vá às compras. Eu dou a ele um pedacinho de papel com as marcas "cinco maçãs vermelhas". Ele leva o papel até o vendedor, que abre uma gaveta marcada "maçãs"; depois ele olha para a palavra "vermelho" numa tabela na sua frente e encontra a amostra de cor ao lado; depois ele pronuncia a série de números naturais - assumo que a saiba de cabeça - até chegar ao número "cinco", e enquanto pronuncia cada número, ele tira da gaveta uma maçã da mesma cor que a amostra da tabela (Wittgenstein, 2009 , p. 5e e 6e).

O que o jogo de linguagem do vendedor de maçãs evidencia? Evidencia, talvez com a eficácia similar de um contrafactual, o resultado prático, a implicação contextual, da imagem sobre a natureza da linguagem que encontramos na citação de Santo Agostinho, na concepção inicial de Wittgenstein no Tractatus Logico-Philosophicus e também em nossas teses estereotipadas pelo formalismo sobre a natureza da linguagem. Aceitar a tese de que toda a linguagem opera sua significação pela via de um processo designativo implica a aceitação de que é desse modo (o modo do vendedor de maçãs) que empregamos a linguagem em nossa vida ordinária. E esse não parece ser, definitivamente, o caso.

Similarmente, a noção de formas de vida aparece em Investigações Filosóficas como outro expediente reflexivo que procura ressaltar o fato de que os seres humanos estão socialmente vinculados por atividades específicas que constituem, para eles, a sua forma de vida. Wittgenstein emprega a expressão forma de vida (Lebensform) cinco vezes em 
Investigações Filosóficas ${ }^{7}$. Dessas cinco ocorrências, quatro nos parecem particularmente relevantes.

Na primeira ocasião, no parágrafo 19 , Wittgenstein a emprega depois de discutir em que sentido poderíamos pensar uma linguagem como algo 'completo' ou 'incompleto'; e sugere a possibilidade de cogitarmos a existência de linguagens bem mais simples que a nossa linguagem comum (ou ordinária) e que poderiam consistir somente de (1) ordens ou de (2) perguntas e respostas do tipo 'sim' ou 'não'. E encerra a sua reflexão assumindo que "imaginar uma linguagem significa imaginar uma forma de vida" (Ibidem, p. 11e). A sugestão de que não faria sentido aplicar as categorias de 'completo' ou 'incompleto' à linguagem diante da possibilidade de conceber exemplos de linguagens bem menos arrojadas que a linguagem humana, procura evidenciar que a aplicação dessas categorias simplesmente não faz sentido quando levamos em consideração o fato de que uma linguagem é algo que se encontra incorporado num contexto específico de uso e de atividade, ou seja, numa forma de vida. O ponto ganha ainda mais clareza adiante, considerando as demais ocorrências da expressão.

Na segunda ocasião, no parágrafo 23 , Wittgenstein vinculará o emprego do termo jogo de linguagem ao termo forma de vida procurando indicar com isso que ambas expressões enfatizam o contexto vivo do uso da linguagem: “A palavra 'jogo de linguagem' é usada aqui para enfatizar o fato de que o falar da linguagem é parte de uma atividade, ou de uma forma de vida" (Ibidem, p. 15e). Assim, a diversidade de ações enumeradas na sequência por Wittgenstein (dar e receber ordens, descrever objetos, construí-los a partir de uma descrição ou desenho, fazer uma narrativa, testar e formular uma hipótese, atuar, adivinhar algo em charadas, resolver problemas aritméticos, traduzir, etc.) correspondem a jogos de linguagem porque expressam atividades específicas dentro de contextos igualmente específicos e que envolvem o uso da linguagem pelos seres humanos. Ademais, a passagem de Wittgenstein procura enfatizar que todas essas coisas diferentes só podem ser realizadas precisamente porque os seres humanos se encontram organizados pela linguagem e através dela, de modo que ela constitui para eles a sua forma de vida.

Já na terceira ocorrência, no parágrafo 241, Wittgenstein aborda a questão do 'acordo' e do 'desacordo' em relação a determinada asserção ou proposição. E essa ocorrência da expressão forma de vida é particularmente relevante, porque é através dela que Wittgenstein assenta o caráter determinante da linguagem no que poderíamos entender como uma forma de vida humana. Ele diz que "é na sua [their] linguagem que seres humanos concordam. Essa concordância não é uma concordância em opiniões, mas em forma de vida" (Ibidem, p. 94e, itálico nosso).

E, por fim, no parágrafo 345, Wittgenstein refere a forma de vida como algo que é da ordem do dado, como algo natural: "O que se precisa aceitar, o dado [the given], são, dir-seá, as formas de vida" (Ibidem, p. 238e, itálico nosso). Dado, aqui, precisa ser entendido como algo que não é primordialmente natural, mas que poderá vir a naturalizar-se. Ou seja, aquilo que ganha, conforme já mencionamos, o estatuto de uma segunda natureza.

Gostaríamos de sugerir, portanto, que o emprego da expressão formas de vida em Investigações Filosóficas promove a recondução do debate sobre os modos de explicação 
filosófica do fenômeno de significação linguística para o território das considerações sobre as práticas, os hábitos e os contextos de uso da linguagem, onde são vistos como determinantes para a fixação do significado de um termo (ou comportamento) específico ${ }^{8}$.

É, portanto, a partir da filosofia tardia de Wittgenstein com suas relevantes noções de jogos de linguagem e formas de vida a sugerirem a ideia de uma necessária impregnação da linguagem nos contextos humanos concretos e vivos, que podemos pensar na noção de gramática. De acordo com João José de Almeida (2008):

Uma gramática, no sentido utilizado por Wittgenstein, é o conjunto de normas que descreve o uso de expressões (Wittgenstein, 2001, §469). Diz respeito, portanto, à determinação dos significados de palavras, de sinais, gestos, ou qualquer outro elemento significativo no contexto do seu emprego [ou seja, linguagens], no quadro da sua execução ou na forma de vida na qual o seu sentido pode ser compreendido. Por esse motivo, poderíamos imaginar três definições sinônimas [...] do que poderia ser uma gramática: (1) a de que ela é um conjunto fechado de relações internas que dá conta de sentidos e significados de um ponto de vista pragmático; ou, (2) de que se trata de um comportamento linguístico correlacionado a uma visão de mundo vivida com o caráter de necessidade; ou, (3) a de que ela não pode ser senão uma espécie de metafísica operatória dada na cultura. Em síntese, uma gramática [para Wittgenstein] [...] está longe de aludir a normas sintáticas e semânticas que regem a aplicação de uma língua. Diz respeito, antes, ao espaço bem mais amplo do emprego de convenções culturais que explicam, em termos de regras, o entrelaçamento pragmático entre sentido e significado (Almeida, 2008, p. 66).

Nesse ponto, é crucial fazer um esclarecimento. Iniciamos esta seção falando, exclusivamente, sobre a linguagem e sobre o fenômeno de significação linguística e, com base em Wittgenstein, pretendemos argumentar que a significação linguística tira sua eficácia e sua relevância do fato de que a linguagem se encontra necessariamente corporificada em uma diversidade de jogos de linguagem complexos imanentes a uma forma de vida igualmente complexa. Haveria, portanto, por trás do argumento, a sugestão de que o comportamento humano - incluindo nele os comportamentos linguísticos - derivaria seu sentido e significação precisamente em função dessa incorporação gramatical na forma de vida humana com seus jogos de linguagem. Se a gramática, como pretendeu Wittgenstein, está longe de referir ao sistema de normas sintáticas e semânticas que regem a utilização de uma língua e está, então, mais próxima de um espaço de vigência daquelas convenções da própria cultura que dão conta da unidade entre sentido e significado (significação), então seria lícito admitir que existe também uma gramática que determina todos os processos de atribuição de sentido relativos, por exemplo, à educação 9 .

O argumento, aqui, apresenta uma minúcia para qual é importante chamar a atenção. Não se trata de entender o campo da educação, a partir dessa introdução específica da noção de gramática em Wittgenstein, como uma disciplina teórica ou uma ciência. E isso porque, fundamentalmente, a distinção entre 'científico' e 'gramatical' é uma distinção de ordem 
relacional, onde o 'gramatical' tira suas relações da imanência do empírico que estão situadas, precisamente, fora da linguagem; e, assim, apresentam suas normas e convenções numa relação de constituição necessária com o empírico, emanam-se dele, embora independam dele (Almeida, 2008, p. 66 e 67). Assim, os sentidos 2 e 3 mencionados por Almeida (2008) apresentam a gramática numa acepção que a aproxima de sua incorporação cultural e prática, tanto como algo que se relaciona mutuamente com uma certa visão de mundo quanto como algo que suscita uma metafísica operante na própria cultura. Ora, reconhecer, portanto, a existência de uma gramática que incorpora a educação a partir de Wittgenstein implica reconhecer a existência de um contexto amplo constituído por convenções, discursos, práticas, instituições e pessoas a partir do qual são consteladas relações que fixam o próprio sentido de determinadas práticas. Disso se segue um pressuposto importante sobre a singularidade e sobre como ela determina esse campo. Cabe aqui evocar essa aproximação conforme sugere Almeida (2008):

Lacan e Wittgenstein [...] não mobilizam propriamente atos de fala num sentido classificatório dessa expressão, nem colocam o acento filosófico em qualquer componente abstrato da linguagem, como o sentido, a interpretação, a racionalidade, a verdade ou a regra. Nesses autores, [...] a linguagem é retomada como ato, ou mais propriamente, como fala. A linguagem é tratada, portanto, em primeira pessoa, como ato de um indivíduo, de um sujeito, e não de um objeto inanimado em terceira pessoa, como é o caso da abstração teórica. $\mathrm{O}$ ato inaugura uma certa lógica, que, tanto para Wittgenstein como para Lacan, não é a mesma lógica que predetermina e classifica os tipos de ação dos proferimentos, senão a lógica própria do ato. $\mathrm{E}$, dessa forma, o ato sempre implica o significado profundo do acontecimento para o sujeito que o comete, não para uma coletividade em geral e em abstrato. (Almeida, 2008, p. 73-74).

A aproximação entre Wittgenstein e Lacan é sugerida através da noção de singular, já que para o Wittgenstein tardio a linguagem não pode nunca ser pensada fora de sua incorporação concreta sob o risco de que isso mate a própria linguagem (McGinn, 1997) e já que para Lacan a linguagem é, pelo menos à primeira vista, pensada a partir do empreendimento linguístico de Saussure (Juranville, 1987). Sugerir, portanto, a linguagem como estando intimamente vinculada a um ato de fala ou proferimento reconduz, à primeira vista, a discussão filosófica sobre a linguagem à dimensão subjetiva concernente à primeira pessoa; mas se compreendemos a subjetividade como algo que se constitui na alteridade, desdobra-se também daí o aspecto contextual no qual a linguagem se incorpora e que suscita uma gramática. No entanto, a exploração do encontro entre esses registros (individual e social, subjetivo e cultural, subjetividade e alteridade) no que diz respeito à linguagem é algo que poderá ser explorado em próximos trabalhos. 


\section{Considerações Finais}

Procuramos ao longo do artigo sugerir que uma reorientação de certos pressupostos filosóficos subjacentes ao campo da educação especial é pertinente, dado que indicamos a existência de uma pergunta frequentemente esquecida relativa ao sujeito da educação especial. Os modos como se fundamentarão os elementos que respondem a essa pergunta configuram o próprio tratamento, bem como os serviços disponibilizados. De modo que uma resposta capaz de chamar atenção para o aspecto da linguagem como crucial à compreensão de uma certa ideia de humanidade parece ainda pouco explorado exatamente porque não opera aquele reconhecimento lesivo que mencionamos, o qual reduz os sujeitos à materialidades calcadas no biológico. Nossa proposta, diametralmente distinta dessa, procura reconduzir o debate aos modos de incorporação social e cultural da linguagem e como, pela linguagem, pode-se pensar a constituição subjetiva. $\mathrm{O}$ contexto escolar, que demanda por processos constituidores de autonomia, onde a linguagem e o que ela disponibiliza a partir da ideia de lugar de elaboração, criação de narrativas e encontro com a alteridade, apresentase portando como um locus privilegiado de pesquisa sobre a linguagem e suas formas de incorporação. Também nos parece legítimo sugerir que é no campo da educação especial desde sempre pregnante de condições de exclusão, produção de anormalidade e, logo, produtor de estigmatização - que essas reflexões são mais urgentes. Entendemos que o sujeito da educação especial, antes de ser classificado por manuais de transtornos mentais ou doenças que operam uma tipologia redutora de sua existência, é um sujeito que emprega a linguagem, elabora suas experiências e encontra-se inserido na forma de vida humana.

\section{Notas}

1. O presente trabalho foi realizado com apoio da Coordenação de Aperfeiçoamento de Pessoal de Nível Superior - Brasil (CAPES) - Código de Financiamento 001 / This study was financed in part by the Coordenação de Aperfeiçoamento de Pessoal de Nível Superior - Brasil (CAPES) - Finance Code 001

2. A título de informação, destacamos particularmente uma aposta em um gênero de escrita capaz de desdobrar uma narrativa sobre a experiência formativa (Hermann, 2016) enquanto produção de subjetividades. Essa narrativa, para nós, se dá na escritura de cartas. Tomamos a carta como um dispositivo estruturante da formação. Em trabalhos anteriores apresentamos alguns resultados preliminares que aqui nos servem de apoio. Em Lima e Vasques (2018) é possível rastrear tanto o surgimento como a consolidação de um interesse crescente pelas cartas em um grupo de trabalho e de pesquisa vinculado ao Programa de Pós-Graduação em Educação da Universidade Federal do Rio Grande do Sul. E a partir de Mautone (2018) é possível encontrar uma sistematização filosófica do gênero da carta enquanto escritura, na qual aparecem conceitos como endereçamento, comunicação e correspondência. Diante das experiências construídas a partir da formação de professores e diante das cartas é que sugeriremos uma nova possibilidade de pesquisa dentro do campo, que convoca novamente um questionamento sobre seus próprios fundamentos.

3. Descartes pretende evitar essas duas dificuldades na fundamentação do sistema do conhecimento ao recorrer, como também fez Aristóteles, à noção de proposições indemonstráveis, ou seja, aquelas cuja verdade seria autoevidente, prescindindo de demonstração. Por essa razão, Descartes introduz os critérios de clareza e distinção como reguladores do que se pode ter certeza ou, dito de outro modo, daquilo que é verdadeiro em si mesmo e por si mesmo. O método do ceticismo radical, que coloca sob dúvida todas as proposições antes dadas por certas, procura empreender uma testagem das próprias proposições que eram tomadas como candidatas fortes a proposições indemonstráveis. Encontrar, portanto, uma proposição clara e distinta para a fundação do edifício do conhecimento corresponderia ao encontro de uma 
proposição cuja verdade seria autoevidente. O Cogito, nas suas Meditações Metafísicas, cumpre esse papel de fundação a partir da qual se poderá estabelecer com rigor a cadeia de proposições que sistematizariam o conhecimento, sem cair em regresso ao infinito ou circularidade.

4. Plaisance (2015) usa a expressão visões em negativo, tomamos esse uso como uma analogia com o fotográfico, na qual o filme guarda o negativo da imagem que será revelada.

5. Poder-se-ia indicar preliminarmente que a definição de estigma em Goffman (2008) envolve, pelo menos, duas condições analíticas específicas: (i) ser um atributo; (ii) constituir-se como marca real ou metafórica.

6. Adiantamos ao leitor que todas as citações diretas em outro idioma (que não o português) presentes neste texto foram traduzidas por nós para o português e são, portanto, de nossa inteira responsabilidade. Desse modo, daqui em diante nos furtaremos de indicar as ocorrências dessa decisão.

7. Investigações Filosóficas é uma obra cuja edição atual apresenta duas partes. Como Wittgenstein não a publicou em vida, mas se trata de um texto organizado e publicado pelos responsáveis por seu espólio, resta uma discussão a respeito de se estaria nos planos de seu autor inserir a segunda parte na versão final do livro. Isso é relevante no contexto ao qual estamos nos referindo, porque uma das ocorrências de formas de vida consta nesta segunda parte referida.

8. Cavell (1997) sugere que a expressão forma de vida é mais adequadamente pensada a partir de dois eixos - a saber, um eixo horizontal, ou etnográfico, e um eixo vertical, ou biológico. Com isso, ele procura se distanciar de leituras excessivamente convencionalistas do termo e, portanto, que tomam a contribuição de Wittgenstein em Investigações Filosóficas enquanto uma proposta contextualista forte para a explicação da significação (Cavell, 1997, p. 45). Embora Cavell não recuse tout court uma leitura contextualista do segundo Wittgenstein, sua proposta parece mostrar que ela precisa ser nuançada também por uma consideração séria sobre as complexidades vitais que a dimensão do biológico suscita. Parece-nos, ademais, que sua proposta procura deflacionar algumas interpretações de Investigações Filosóficas que a tomaram como defensora de certo conservadorismo no campo da ética. Nesse sentido, Cavell se refere, especificamente, a Bertrand Russell e Ernst Gellner como autores que "reagiram ao apelo do livro ao ordinário e ao cotidiano como expressão de um receio, por assim dizer, petit bourgeois de mudança, quer por parte da inventiva individual, quer da revolução social" (Cavell, Op. Cit., p. 47.)

9. A distinção, efetuada por Saussure, entre 'língua' e 'linguagem' é, aqui, evocada. E se não for levada em consideração, reduzirá o argumento como um todo, especialmente o que segue, a uma compreensão errônea sobre a dimensão da linguagem - sobretudo, por defini-la estritamente como algo da ordem da língua, do linguageiro. Tomamos 'linguagem' de modo mais amplo. Cf Saussure, 2012.

\section{Referências}

ALMEIDA, João José Rodrigues Lima de. A gramática da psicanálise. Philósophos, Goiânia, v.13, n. 2, p. 61 83, jul./dez. 2008. Disponível em <https://www.revistas.ufg.br/philosophos/article/view/6836/6717> Acesso em 20/01/2020.

AMERICAN PSYCHIATRIC ASSOCIATION. Manual diagnóstico e estatísticos de transtornos mentais. 5a . ed. (DSM-5). Porto Alegre: Artmed, 2014.

BAPTISTA, Claudio Roberto. Política pública, Educação Especial e escolarização no Brasil. Educ. Pesqui., São Paulo, v.45, e217423, 2019. Disponível em: <http://www.scielo.br/scielo.php?script=sci_arttext\&pid= S1517-97022019000100407\&lng=en\&nrm=iso>. Acessado em: 27 Jan. 2020. Epub Oct 21, 2019. http://dx.doi.org/10.1590/s1678-4634201945217423.

BUENO, José Geraldo Silveira. A produção social da identidade do anormal. IN: FREITAS, Marcos Cezar de (org.). História social da infância no Brasil. São Paulo: Cortez. 2003.

CARROLL, Noël. Filosofia da Arte. Lisboa: Edições Texto \& Grafia, 2010.

CAVELL, Stanley. Esta América nova, ainda inabordável - Palestras a partir de Emerson e Wittgenstein. São Paulo: Editora 34, 1997.

FERREIRA, C. M. D. R. J. Às sombras das escalas: um estudo sobre a concepção de anormalidade em Alfred Binet. Belo Horizonte: Fino Traço, 2016. 168 p. 
GOFFMAN, Erving. Estigma: Notas sobre a manipulação da identidade deteriorada. São Paulo: LTC. 2008.

GUEROULT, Martial. Descartes' Philosophy Interpreted According to the Order of Reasons. Minneapolis: University of Minnesota Press, 1984.

HERMANN, N. Entrevista: Conversando com Nadja Hermann. IN: RAJOBAC, R.; BOMBASSARO, L. C.; GOERGEN, P. Experiência formativa e reflexão: Homenagem a Nadja Hermann. Caxias do Sul: Educs, 2016. p. 14-28.

JANUZZI, Gilberta Sampaio de Martino. A educação do deficiente no Brasil: dos primórdios ao início do século XXI. 3.ed.rev. Campinas: Autores Associados, 2012. 211 p.

JURANVILLE, Alain. Lacan e a Filosofia. Rio de Janeiro: Jorge Zahar Editor, 1987.

KASSAR, Mônica de Carvalho Magalhães; REBELO, Andressa Santos; OLIVEIRA, Regina Tereza Cestari de. Embates e disputas na política nacional de Educação Especial brasileira. Educ. Pesqui., São Paulo, v. 45, e217170, 2019. Disponível em <http://www.scielo.br/scielo.php?script=sci_arttext\&pid=S151797022019000100405\&lng=en\&nrm=iso>. Acessado em 27 Jan. 2020. Epub Aug 29, 2019. http://dx.doi.org/10.1590/s1678-4634201945217170.

LIMA, André Luís de Souza; VASQUES, Carla K. Epistemologias em jogo na educação especial. Revista Educação Especial em Debate | v. 2 | n. $05 \mid$ p. 60-76 | jan./jun.2018 Disponível em: <http://periodicos.ufes.br/REED/article/view/17822>. Acesso em 19/01/2019.

MAUTONE, Guilherme. O que nos diz uma carta? Aproximações ensaísticas para uma filosofia epistolar. Disponível em: <https://www.academia.edu/42104146/O_que_nos_diz_uma_carta_Aproxima\%C3\%A7\% C3\%B5es_ensa\%C3\%ADsticas_para_uma_filosofia_epistolar_por_Guilherme_Mautone>. Acesso em 20/01/2019

MAZZOTTA, Marcos José da Silveira. Educação Especial no Brasil: história e políticas públicas. São Paulo: Cortez Editor, 1996.

MCGINN, Marie. Wittgenstein and the Philosophical Investigations. Londres: Taylor \& Francis, 1997.

ORGANIZAÇÃO MUNDIAL DA SAÚDE. CID-10. Classificação Estatística Internacional de Doenças e Problemas Relacionados à Saúde. 10a rev. São Paulo: Universidade de São Paulo; 1997

PLAISANCE, Eric. Da educação especial à educação inclusiva: esclarecendo palavras para definir práticas. Educação (Porto Alegre, impresso), v. 38, n. 2, p. 230-238, maio-ago. 2015. Disponível em <http://revistaseletronicas.pucrs.br/ojs/index.php/faced/article/view/20049/13661>. Acessado em $27 \mathrm{de}$ janeiro de 2020.

SAUSSURE, Ferdinand de. Curso de Linguística Geral. Editora Cultrix, São Paulo, 2012

STERN, David. Wittgenstein's Philosophical Investigations: An Introduction. Cambridge: Cambridge University Press, 2004.

ULLRICH, W.; VASQUES, C. O outro na educação especial: uma abordagem pela lente do reconhecimento. Currículo sem fronteiras, v.17, n.2, p.290-314, maio/ago. 2017. Disponível em <https://periodicos.sbu.unicamp.br/ojs/index.php/etd/issue/view/1596> Acesso em 20/01/2020

VOLTOLINI, Rinaldo. Ethical Interpellation to Inclusive Education. Educ. Real., Porto Alegre, v. 44, n. 1, e84847, 2019. Disponível em <http://www.scielo.br/scielo.php?script=sci_arttext\&pid=S217562362019000100204\&lng=pt\&nrm=iso>. acessos em 27 jan. 2020. Epub 07-Mar-2019. http://dx.doi.org/10.1590/2175-623684847.

WITTGENSTEIN, Ludwig. Philosophische Untersuchungen - Philosophical Investigations. Oxford: BasilBlackwell, 2009.

WITTGENSTEIN, Ludwig. Tractatus Logico-Philosophicus. Londres: Routledge, 2001. 


\section{Correspondência}

Guilherme Mautone: É Doutor, Mestre e Bacharel em Filosofia pela UFRGS. Desenvolve pesquisa na área de estética e filosofia da arte, com bolsa CAPES.

ORCID: 0000-0001-8623-6230.

E-mail: guimautone@gmail.com.

André Luís de Souza Lima: É Licenciado em Filosofia, Mestre e doutorando em Educação pela UFRGS, com bolsa CAPES. Integrante da Rede Internacional de Pesquisa em Psicanálise, Educação e Política (RIPPEP). Pesquisador do Núcleo de Pesquisa em Psicanálise, Educação e Cultura - NUPPEC.

ORCID: 0000-0002-5144-714x.

E-mail: andre.lima@ufrgs.br.

Carla K. Vasques: Professora associada da Faculdade de Educação da UFRGS. Psicóloga, Mestre e Doutora em Educação pela UFRGS. Professora do PPGEDU/UFRGS. Integrante da Rede Internacional de Pesquisa em Psicanálise, Educação e Política (RIPPEP), Coordenadora do Núcleo de Pesquisa em Psicanálise, Educação e Cultura - NUPPEC (eixo 1).

ORCID: 0000-0002-3284-8749.

E-mail: k.recuero@gmail.com.

Texto publicado em Currículo sem Fronteiras com autorização dos autores. 